\title{
High Resolution Melting Curve Assay for Detecting rs12979860 IL28B Polymorphisms Involved in Response of Iranian Patients to Chronic Hepatitis C Treatment
}

\author{
Abolfazl Fateh ${ }^{1}$, Mohammad Reza Aghasadeghi ${ }^{2}$, Hossein Keyvani ${ }^{3}$,Hamid Reza \\ Mollaie $^{3}$, Shamsi Yari ${ }^{4}$, Ali Reza Hadizade Tasbiti ${ }^{4}$, Morteza Ghazanfari ${ }^{4}$, Seyed \\ Hamid Reza Monavari ${ }^{3 *}$
}

\begin{abstract}
Background: A recent genome-wide association study (GWAS) on patients with chronic hepatitis C (CHC) treated with peginterferon and ribavirin (pegIFN- $\alpha /$ RBV) identified a single nucleotide polymorphism (SNP) on chromosome 19 (rs12979860) which was strongly associated with a sustained virological response (SVR). The aim of this study was twofold: to study the relationship between IL28B rs12979860 and sustained virological response (SVR) to pegIFN- $\alpha /$ RVB therapy among CHC patients and to detect the rs12979860 polymorphism by high resolution melting curve (HRM) assay as a simple, fast, sensitive, and inexpensive method. Materials and Methods: The study examined outcomes in 100 patients with chronic hepatitis $\mathbf{C}$ in $\mathbf{2}$ provinces of Iran from December 2011 to June 2013. Two methods were applied to detect IL28B polymorphisms: PCR-sequencing as a gold standard method and HRM as a simple, fast, sensitive, and inexpensive method. Results: The frequencies of IL28B rs12979860 CC, CT, and TT alleles in chronic hepatitis C genotype 1a patients were $10 \%(10 / 100), 35 \%$ $(35 / 100)$, and $6 \%(6 / 100)$ and in genotype $3 \mathrm{a}$ were $13 \%(13 / 100), 31 \%(31 / 100)$, and $5 \%(5 / 100)$, respectively. In genotype 3a infected patients, rs12979860 (CC and $\mathrm{CT}$ alleles) and in genotype 1a infected patients (CC allele) were significantly associated with a sustained virological response (SVR). The SVR rates for CC, CT and TT (IL28B rs12979860) were $18 \%, 34 \%$ and 4\%, respectively. Multiple logistic regression analysis identified two independent factors that were significantly associated with SVR: IL-28B genotype (rs 12979860 CC vs TT and CT; odds ratio [ORs], 7.86 and 4.084, respectively), and HCV subtype 1a (OR, 7.46). In the present study, an association between SVR rates and IL28B polymorphisms was observed. Conclusions: The HRM assay described herein is rapid, inexpensive, sensitive and accurate for detecting rs12979860 alleles in CHC patients. This method can be readily adopted by any molecular diagnostic laboratory with HRM capability and will be clinically beneficial in predicting treatment response in HCV genotype 1 and 3 infected patients. In addition, it was demonstrated that $\mathrm{CC}$ and $\mathrm{CT}$ alleles in $\mathrm{HCV}-3 \mathrm{a}$ and the $\mathrm{CC}$ allele in $\mathrm{HCV}$-1a were significantly associated with response to pegIFN- $\alpha / \mathrm{RBV}$ treatment. The present results may help identify subjects for whom the therapy might be successful.
\end{abstract}

Keywords: Chronic hepatitis C - single nucleotide polymorphism - sustained virological response

Asian Pac J Cancer Prev, 16 (5), 1873-1880

\section{Introduction}

Hepatitis $\mathrm{C}$ virus (HCV) is an important public health problem worldwide that causes acute and chronic liver diseases like cancer. Approximately $80 \%$ of subjects with acute hepatitis $\mathrm{C}$ progress into a chronic disease. Chronic hepatitis $\mathrm{C}$ virus (CHC) infection is an important cause for developing (10-20\%) cirrhosis and hepatocellular carcinoma (HCC) that often results in liver failure and thus in liver transplantation (Keyvani et al., 2012). HCC is the seventh most common cancer worldwide and the third most common cause of cancer mortality (Yang and Roberts., 2010). HCC usually expands in patients infected with chronic hepatitis B (HBV) or chronic hepatitis $\mathrm{C}$ (CHC). HBV vaccination programs among general population in high risk areas and using antiviral treatment in chronic hepatitis $\mathrm{C}$ and $\mathrm{B}$, could be prevented liver cancer (Su et al., 2013). In Iran, incidence of hepatocellular carcinoma is low because most cases are due to HBV and this infection was less common (Pourhoseingholi et al., 2010).

Although successful execution of direct-acting

${ }^{1}$ Department of Virology, School of Public Health, Tehran University of Medical Sciences, ${ }^{2}$ Department of Hepatitis and AIDS, Pasteur Institute of Iran, ${ }^{3}$ Departments of Virology, Iran University of Medical Sciences, ${ }^{4}$ Departments of Mycobacteriology and Pulmonary Research, Pasteur Institute of Iran, Tehran, Iran ${ }^{\circledR}$ Equal contributors *For correspondence: hrmonavari@yahoo.com 
antiviral therapy was recently demonstrated in Western countries, combination pegylated interferon-alpha (pegIFN- $\alpha$ ) plus ribavirin (RBV) (pegIFN- $\alpha /$ RVB) is still the most effective treatment for patients with $\mathrm{CHC}$ in central Asia (Beinhardt et al., 2013; Ghany et al., 2009). Standard of care (SOC) for treatment of CHC infection is pegIFN- $\alpha / \mathrm{RVB}$, that leads to sustained virological response (SVR) in about $40 \%-60 \%$ of subjects with CHC genotype 1 (HCV-1) and $80 \%$ or more in those with genotypes 2 and 3 of this infection (Tsubota et al., 2011). Higher SVR rates have been obtained in subjects infected with other HCV genotypes (Ge et al., 2009; Antaki et al., 2010; Tsubota et al., 2011; European Association for the Study of the Liver., 2014) and middle SVR rates have been obtained in those with HCV genotype 4 (Antaki et al., 2010). Interestingly, Iranian patients with CHC respond better to SOC treatment (Alavian et al., 2010). Of the various host (age, sex, body mass index, race, usage immunosuppressive drugs, host genetic, sex, stage of fibrosis, coinfection with other hepatitis viruses and human immunodeficiency virus) and viral factors (HCV genotype, HCV viral load) associated with the effectiveness of pegIFN- $\alpha /$ RVB therapy (European Association for the Study of the Liver., 2014).

A recent genome-wide association study (GWAS) on patients with $\mathrm{CHC}$ treated with pegIFN- $\alpha /$ RVB identified a single nucleotide polymorphism (SNP) on chromosome 19 (rs 12979860 and rs8099917) that was strongly associated with sustained virological response (SVR). The CC alleles (rs12979860) and TT alleles (rs8099917) were associated with SVR compared with the TT (rs12979860) and GG (rs8099917) alleles which increasing the possibility that the $\mathrm{C}$ allele may favour spontaneous clearance of $\mathrm{HCV}$ (Ge et al., 2009). There are different opinions for clinical determination of IL28B testing; but, it seems that it can help in decision-making with regard to treatment (Grebely et al., 2010). IL28B alleles are the robust pretreatment prognosticator of SVR to pegIFN- $\alpha /$ RVB and protease inhibitor triple therapy in patients with $\mathrm{HCV}-1$ infection. Testing may be considered when the patient or provider wants additional information on the probability of treatment response or the probable duration of the needed treatment (Class 2a, Level B) (Ghany et al., 2011).

Several methods, such as direct DNA sequencing, real-time PCR, amplification refractory mutation system polymerase chain reaction (ARMS-PCR), polymerase chain reaction-restriction fragment length polymorphism (PCR-RFLP) and allele-specific PCR can be used for genotyping SNPs, such as IL28B alleles (Chen et al., 2003).

The aim of this study was twofold: to study the relationship between IL28B rs12979860 and SVR to pegIFN- $\alpha /$ RVB therapy among CHC patients and to detecting rs 12979860 polymorphism by High Resolution Melting Curve (HRM) as a simple, fast, sensitive, and inexpensive method.

\section{Materials and Methods}

\section{Patients}

One hundred $(\mathrm{n}=100)$ patients with chronic hepatitis $\mathrm{C}$ in 2 provinces of Iran (Digestive Disease Research Center of Tehran and Virology Laboratory of the Besat Specialist Clinic of Kerman, IRAN from) from December 2011 to June 2013 enrolled this study.

The exclusion criteria included having other hepatitis virus (hepatitis B and D viruses), using immunosuppressive drugs (organ transplantation), diabetes mellitus, coexistent autoimmune liver diseases and having any of the various diseases that suppress the immune system (human immunodeficiency virus).

\section{Treatment of patients}

One hundred patients were treated with 180 milligram per week (mg/week) of Pegylated interferon alfa-2a

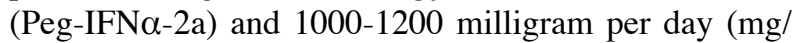
day) of ribavirin (RBV). The patients with chronic HCV genotypes 1a and 3 were treated for 48 and 24 weeks, respectively (Alavian et al., 2010). To determine the end of the treatment, the viral load (HCV RNA) in blood was measured at the end of the treatment and 6 months later. The absence of detectable RNA of HCV in blood for at least 24 weeks after discontinuing treatment was defined as a Sustained Virologic Response (SVR) (Figure 1).

\section{Sample collection}

About $8 \mathrm{~mL}$ blood samples from $\mathrm{HCV}$ patients were collected in Ethylenediaminetetraacetic acid (EDTA) tubes. Plasma was separated and aliquoted. Then, it was stored at $-80^{\circ} \mathrm{C}$ until analysis. Peripheral blood mononuclear cells (PBMCs) were isolated using Ficoll (Ficoll-Paque PLUS, GE Healthcare) and stored at $-20^{\circ} \mathrm{C}$.

\section{RNA and DNA extraction}

HCV RNA was extracted from $200 \mu$ l plasma samples using a high pure RNA isolation kit (Roche, Germany). Purified RNA can be stored at $-80^{\circ} \mathrm{C}$ for later analysis. IL28B DNA was extracted from 200 $\mu$ l PBMC samples using a high pure PCR template preparation kit (Roche, Germany). Purified DNA can be used directly or stored at +2 to $+8^{\circ} \mathrm{C}$ for later analysis. DNA and RNA concentrations were detected by calculating the absorbance ratio OD260nm/280nm using Thermo Scientific $^{\mathrm{TM}}$ NanoDrop-2000 model (Thermo Scientific, Wilmington, DE).

\section{Virologic testing}

$\mathrm{HCV}$ genotyping and HCV viral loading from plasma samples were carried out using the AmpliSens ${ }^{\circledR} \mathrm{HCV}$ 1/2/3-FEP PCR kit and AmpliSens ${ }^{\circledR}$ HCV-Monitor-FRT Real-Time PCR kit (InterLabService Ltd., Moscow) according to the manufacturer's instructions, respectively.

\section{Laboratory procedures}

Liver enzyme function tests were carried out for all the patients. Alanine Aminotransferase (ALT), Aspartate Aminotransferase (AST), and alkaline phosphatase (ALP) were measured on the Selectra E Clinical Chemistry analyzer (Vital Scientific, The Netherlands).

High resolution melting curve (HRM)

IL28B rs12979860C > T alleles were diagnosed from 
PBMC samples using HRM assay. Primer sequences were used for amplifications as follows: forward primer: 5'-CCTGGACGTGGATGGGTA-3' and reverse primer: 5'-GCGCGGAGTGCAATTCAA-3'.

The real-time PCR $(20 \mu \mathrm{l})$ was composed of $10 \mu \mathrm{l}$ of $2 \times$ AccuMelt HRM SuperMix (Quanta BioSciences, Inc, USA), forward and reverse primers $(0.25 \mu$ l of each primer was used), nuclease-free water $(4.5 \mu \mathrm{l})$, and DNA extracted from PBMCs $(5 \mu \mathrm{l})$. The reactions were set up in triplicate in a 96-well PCR plate and processed on a CFX96 Touch $^{\mathrm{TM}}$ Real-Time PCR Detection System (BioRad Laboratories, Inc). CFX Manager Software Version 3.0 (Bio-Rad Laboratories, Inc) was applied to set up the sample arrangement on the PCR plate, to define PCR conditions, to monitor the amplification in real time, to

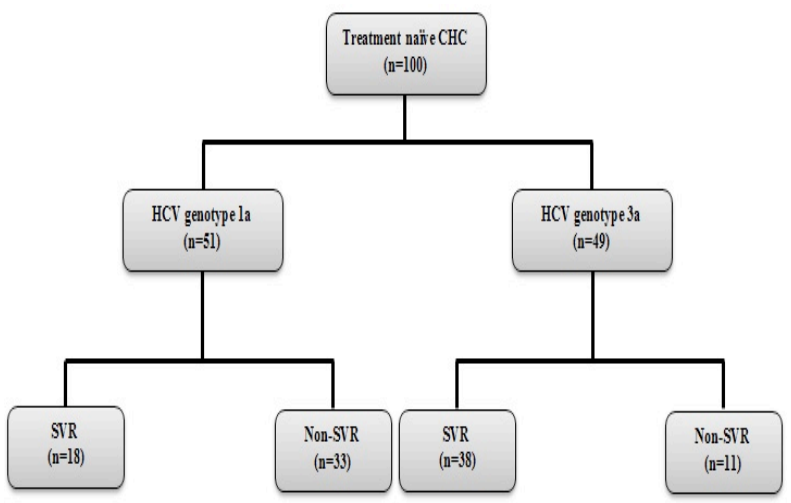

Figure 1. Flow Diagram of the 100 Iranian Patients with Chronic Hepatitis C

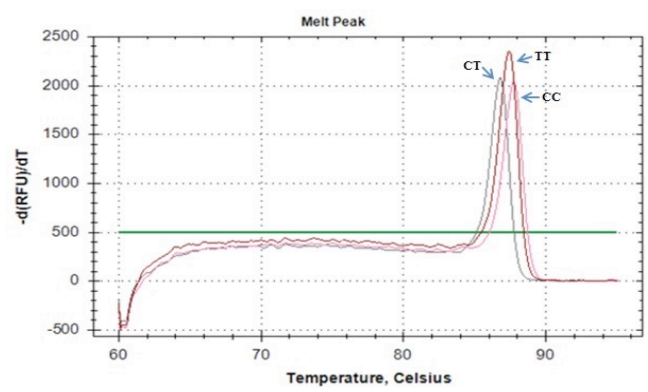

Figure 2. High Resolution Melting Curve (HRM) Analysis for Detection of IL28B rs12979860 Genotype

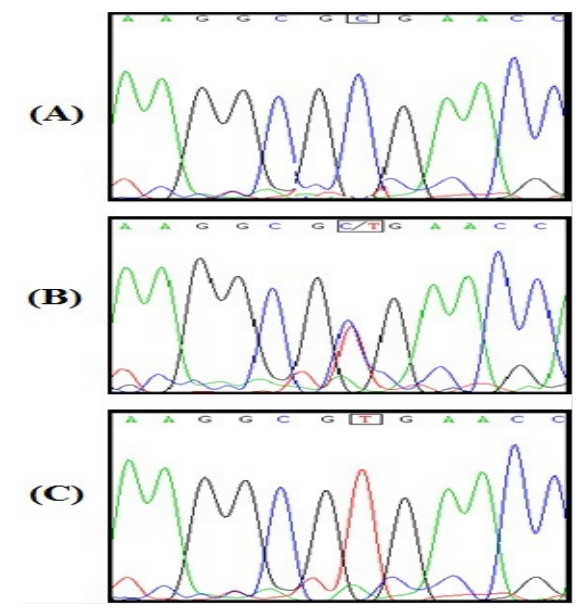

Figure 3. PCR-Sequencing Chromatograms for IL28B rs12979860 Genotype. (A) CC genotype. (B) CT genotype: double peaks at SNP position. (C) TT genotype view melting curves, and to calculate DNA concentrations and other PCR parameters.

The amplification reaction mixture consisted of 30 ng of genomic DNA; the cycling parameters of PCR were as follows: $95^{\circ} \mathrm{C}$ for $5 \mathrm{~min}$ followed by 45 cycles of $95^{\circ} \mathrm{C}$ for $10 \mathrm{~s}, 60^{\circ} \mathrm{C}$ for $30 \mathrm{~s}$, and $60^{\circ} \mathrm{C}$ for $30 \mathrm{~s}$. Then, high-resolution melt curves analysis was carried out by fluorescence acquisition during a temperature increase from $60^{\circ} \mathrm{C}$ to $95^{\circ} \mathrm{C}$, using increments of $0.1^{\circ} \mathrm{C}$ with holding steps of $10 \mathrm{~s}$ (Figure 2).

\section{PCR Sequencing}

To confirm the HRM method, the HRM genotyping results of rs 12979860 should be $100 \%$ compatible with the DNA sequencing consequences. The primers for PCR and sequencing reactions were as follows: forward primer: 5'-CTCTGCACAGTCTGGGATTCCT-3' and reverse primer: 5'-CTGAGGGACCGCTACGTAAGTC-3'. The amplification reaction mixture consisted of 50ng of genomic DNA, forwards and reverse primers $(0.15 \mu \mathrm{M}$ of each), different deoxynucleotides ( $0.2 \mathrm{mM}$ of each), Ex Taq DNA Polymerase (1.5U) (Takara, Korea Biomedical, Inc), and PCR buffer (10X) containing $1.5 \mathrm{mM} \mathrm{MgCl}$. First, the PCR was performed by denaturing the samples (for $10 \mathrm{~min}$ at $95^{\circ} \mathrm{C}$ ); then, 35 cycles including $95^{\circ} \mathrm{C}$ for $45 \mathrm{~s}, 66^{\circ} \mathrm{C}$ for $45 \mathrm{~s}, 72^{\circ} \mathrm{C}$ for $45 \mathrm{~s}$, and a final extension at $72^{\circ} \mathrm{C}$ for $10 \mathrm{~min}$ were followed. Electrophoresis of the PCR products were carried out on the agarose gels (1\%). PCR products (390 bp) were purified by High Pure PCR Product Purification Kit (Roche, Germany) then, three IL28B 12979860 genotypes (TT, CT and CC) were analyzed by direct sequencing (Figure 3 ).

\section{Statistical analysis}

All the calculations were performed using SPSS version 21 software (SPSS, Inc., Chicago, IL). Predictors for SVR were evaluated by multivariate logistic regression analysis. Multivariate analysis included all significant parameters from univariate analysis as well as the parameters that were available from all patients. Analysis of continuous variables was performed using independentsamples t-test and Kruskal-Wallis test. $\chi^{2}$ and Fisher's exact tests were used for comparing frequency data and evaluating the relationships between groups. Differences with the $\mathrm{p}$-value of $>0.05$ were considered statistically significant.

\section{Ethics statement}

The current study was approved by Ethical Committee of School of Public Health, Tehran University of Medical Sciences. An informed consent was also directly obtained from each patient.

\section{Results}

\section{Patient characteristics}

One hundred patients $(n=100)$ with chronic HCV infection were followed up in this study. There were 51 patients $(n=51)$ with HCV genotype $1 \mathrm{a}$ and 49 patients $(n=49)$ with HCV genotype $3 \mathrm{a}$ infection. Mean age of

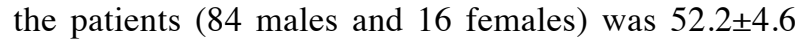


(ranging from 41 to 61 years old). Pretreatment clinical and virological characterizations including alanine transaminase (ALT), aspartate aminotransferase (AST), alkaline phosphatase (ALKP), HCV genotype, and HCV viral load are showed in Table 1.There were no significant differences between HCV genotypes and age, ALT, AST, and ALKP levels, whiles they were significantly different from HCV viral load ( $\mathrm{p}=0.018$ ).

The sustained virological response (SVR) rate in the patients with $\mathrm{HCV}$ genotype $1 \mathrm{a}$ and $3 \mathrm{a}$ infection was 18 (35.3\%) and 38 (77.55\%), respectively. SVR rate in HCV genotype 1a was significantly less than of the patients with $\mathrm{HCV}$ genotype $3 \mathrm{a}(\mathrm{p}=<0.001)$ (Figure 1). Among the HCV genotype 1a and HCV genotype 3a groups, 33 (64.7\%) and $11(22.45 \%)$ patients were non-responders (NonSVR). No significant differences were found between the HCV treatment response (SVR) and age, sex, baseline liver enzymes levels (ALT, AST, and ALKP), whereas a significant relationship between SVR rate and HCV viral load was shown ( $\mathrm{p}=0.041)$ (Table 2).

Prevalence of rs 12979860 genotype according to $\mathrm{HCV}$ genotypes

In the current study, prevalence of rs 12979860 genotypes $\mathrm{CC}, \mathrm{CT}$, and TT in HCV genotype 1a was $10(10 \%), 35(35 \%)$, and $6(6 \%)$, respectively and in HCV genotype 3a, it was $13(13 \%), 31(31 \%)$, and 5 $(5 \%)$, respectively (Table 3$)$. No statistically significant difference was seen between rs12979860 genotype and HCV genotype $(\mathrm{p}=0.710)$.

Relationship between rs 12979860 genotypes with Laboratory parameters

Baseline serum ALT, AST, and ALKP levels in the patients with $\mathrm{CC}$ genotype of rs12979860 were $248.8 \pm 245.9,248.8 \pm 245.9$, and 586.4 \pm 360.7 , respectively. Among the patients with non-CC genotype, they were $256.6 \pm 215.3,246.3 \pm 195.1$, and 607.5 \pm 418.8 , respectively. This difference was not statistically significant $(\mathrm{p}=0.661$ vs 0.689) (Table 3).

Baseline viral load in the patients with CC genotype was less than the patients with non-CC genotype of rs 12979860; but, no significant difference was found in the baseline viral load between the patients with $\mathrm{CC}$ genotype and non-CC genotype of rs12979860 $\left(3.3 \times 10^{6} \pm 1.7 \times 10^{6}\right.$ vs $4.6 \times 10^{6} \pm 2.5 \times 10^{6}$ and $4.5 \times 10^{6} \pm 2.4 \times 10^{6}$, respectively, $\mathrm{p}=0.127)$.

Sustained Virological Response Rates According to rs12979860 Genotypes

Out of 100 patients of $\mathrm{CHC}$ subjects, 51 patients (51\%) were infected with HCV genotype 1a and 49 patients $(49 \%)$ with genotype $3 \mathrm{a}$. Among 51 patients with HCV genotype 1a infection, 18 (35.3\%) subjects and 49 patients with $\mathrm{HCV}$ genotype $3 \mathrm{a}$ infection, 38 (77.5\%) subjects were treated, respectively and evaluable on the achievement of SVR. For 18 patients with HCV genotype 1a infection, frequencies of rs $12979860 \mathrm{CC}, \mathrm{CT}$, and TT genotypes in SVR subjects were 6, 11, and 1, respectively, while in non-SVR subjects, the frequencies were 4, 24, and 5, respectively. CC genotype of rs 12979860 was significantly associated with SVR compared to non-CC genotype $(\mathrm{p}=0.032)$.

For 38 patients with HCV genotype $3 \mathrm{a}$ infection, frequencies of rs12979860 CC, CT, and TT genotypes in SVR subjects were 12, 23, and 3, respectively. In contrast, in non-SVR subjects, the frequencies were 1,8 , and 2 , respectively. Two (CC and CT) genotypes of rs 12979860

Table 2. Relationship between Baseline Demographic, Clinical, and Virological Characteristics with Sustained Virological Responders

\begin{tabular}{|c|c|c|c|c|}
\hline Patients Features & SVR & Non-SVR & Total & p-value \\
\hline Number of patients (\%) & 56 & 44 & 100 & - \\
\hline Age (years) & $52.3 \pm 4.4$ & $52.2 \pm 5.0$ & $52.2 \pm 4.6$ & 0.966 \\
\hline Gender (male/female) & $48 / 8$ & $36 / 8$ & $84 / 16$ & 0.784 \\
\hline \multicolumn{5}{|l|}{ HCV genotype } \\
\hline $1 \mathrm{a}$ & $18(35.3 \%)$ & $33(64.7 \%)$ & $51(100 \%)$ & $<0.001 \mathrm{a}$ \\
\hline $3 a$ & $38(77.5 \%)$ & $11(22.5 \%)$ & $49(100 \%)$ & \\
\hline HCV viral load (IU/ml) & $3.8 \times 10^{6} \pm 2.2 \times 10^{6}$ & $4.9 \times 10^{6} \pm 2.5 \times 10^{6}$ & $4.3 \times 10^{6} \pm 2.3 \times 10^{6}$ & $0.041 \mathrm{a}$ \\
\hline Baseline ALT level (IU/L) & $243.9 \pm 248.2$ & $260.2 \pm 205.2$ & $252.1 \pm 226.7$ & 0.236 \\
\hline Baseline AST level (IU/L) & $223.7 \pm 197.8$ & $260.2 \pm 199.0$ & $241.9 \pm 198.4$ & 0.125 \\
\hline Baseline ALK level (IU/L) & $602.5 \pm 402.0$ & $724.8 \pm 490.9$ & $663.6 \pm 446.4$ & 0.27 \\
\hline
\end{tabular}

*SVR, sustained virologic response; ALT, alanine aminotransferase; AST, aspartate aminotransferase; ALKP, alkaline phosphatase. ${ }^{\text {aStatistically Significant }}$

Table 3. Relationship between Baseline Demographic, Clinical, Virological Characteristics and Sustained Virological Responders with rs12979860 IL28B polymorphisms

\begin{tabular}{|c|c|c|c|c|}
\hline \multirow{2}{*}{$\begin{array}{l}\text { IL28B } \\
\text { Variable }\end{array}$} & \multicolumn{3}{|c|}{ rs12979860 } & \multirow[b]{2}{*}{ p-value } \\
\hline & $\mathrm{CC}$ & CT & TT & \\
\hline HCV genotype (1a/3a) & $10 . / 13$ & $35 / 31$ & $6 . / 5$ & 0.71 \\
\hline Baseline viral load (IU/ml) & $3.3 \times 10^{6} \pm 1.7 \times 10^{6}$ & $4.6 \times 10^{6} \pm 2.5 \times 10^{6}$ & $4.5 \times 10^{6} \pm 2.4 \times 10^{6}$ & 0.127 \\
\hline AST (IU/L) & $243.4 \pm 240.1$ & $253.0 \pm 183.3$ & $239.7 \pm 206.9$ & 0.661 \\
\hline ALT (IU/L) & $248.8 \pm 245.9$ & $262.2 \pm 217.3$ & $251.1 \pm 213.3$ & 0.689 \\
\hline $\operatorname{ALKP}(\mathrm{IU} / \mathrm{L})$ & $586.4 \pm 360.7$ & $558.7 \pm 481.6$ & $656.3 \pm 356.0$ & 0.569 \\
\hline SVR & 18 & 34 & 4 & $0.032 \mathrm{a}$ \\
\hline Non-SVR & 5 & 32 & 7 & $0.032 \mathrm{a}$ \\
\hline
\end{tabular}

*SVR, sustained virologic response; ALT, alanine aminotransferase; AST, aspartate aminotransferase; ALKP, alkaline phosphatase; ${ }^{\text {aStatistically Significant }}$ 
Table 1. Characterization, Clinical, and Virological Properties of Iranian Patients with CHC before Anti-Viral Therapy with PEG-IFN2a/Ribavirin

\begin{tabular}{lcccc}
\hline Variable & \multicolumn{3}{c}{ Patients } \\
HCV genotype & $1 \mathrm{a}$ & $3 \mathrm{a}$ & Total & p-value \\
\hline No. $(\%)$ & $51(51 \%)$ & $49(49 \%)$ & $100(100 \%)$ \\
Agea & $52.8 \pm 4.7$ & $51.7 \pm 4.6$ & $52.2 \pm 4.6$ & 0.259 \\
& & & \\
AST (IU/L)a & $261.3 \pm 203.8$ & Laboratory Parameters & $239.3 \pm 197.7$ & 0.31 \\
ALT (IU/L)a & $274.0 \pm 230.1$ & $217.3 \pm 191.6$ & $250.6 \pm 229.2$ & 0.269 \\
ALKP (IU/L)a & $692.3 \pm 487.7$ & $618.7 \pm 397.6$ & $655.5 \pm 442.6$ & 0.411 \\
HCV Viral Load (IU/ml)a & $4.9 \times 10^{6} \pm 2.5 \times 10^{6}$ & $3.7 \times 10^{6} \pm 2.2 \times 10^{6}$ & $4.3 \times 10^{6} \pm 2.4 \times 10^{6}$ & 0.018 \\
\hline *ALT, alanine aminotransferase; AST, aspartate aminotransferase; ALKP, alkaline phosphatase; ${ }^{6}$ Continuous parameters are presented as mean \pm standard deviation
\end{tabular}

were significantly associated with SVR $(\mathrm{p}=0.032)$.

Multiple logistic regression analysis identified two independent factors that were significantly associated with SVR: IL-28B genotype (rs 12979860 CC vs TT and CT; ORs, 7.86 and 4.084, respectively), and HCV subtype la (OR, 7.46) (multivariate regression data not shown).

\section{Discussion}

Many factors are important for the prediction of SVR in the patients with $\mathrm{CHC}$ before the initiation of antiviral therapy. These factors can assist physicians in decisionmaking on whether to start antiviral therapy or not and also motivate patients that might have high odds for virological response. Previous studies have shown that HCV genotype, baseline viral load, age, gender, body mass index (BMI), stage of disease, race, alanine aminotransferase (ALT) level, and host genetic polymorphisms of several genes (human leukocyte antigen, chemokines, interleukins and IFN-stimulated genes) are associated with SVR (; Asselah et al., 2007; Wohnsland et al., 2007; Kau et al., 2008; Dai et al., 2009).

The recently published genome-wide association studies (GWAS) have provided insight into host genetic factors that are predictive of $\mathrm{HCV}$ disease progression and treatment outcome. Although several SNPs have an association with SVR and spontaneous HCV clearance, rs12979860 (CC genotype) and rs8099917 (TT genotype) have been identified by multiple groups with different patient cohorts (Melis et al., 2011).

There are different opinions for the clinical determination of IL28B testing; but, it seems that it can help in decision-making with regard to treatment (Grebely et al., 2010). IL28B alleles are the robust pretreatment prognosticator of SVR to pegIFN- $\alpha /$ RVB and protease inhibitor triple therapy in patients with HCV-1 infection. Testing may be considered when the patient or provider demands additional information on the probability of treatment response or the probable duration of the needed treatment (Class 2a, Level B) (Ghany et al., 2011).

The aim of this study was twofold: to study the relationship between IL28B rs12979860 and the sustained virological response to pegIFN- $\alpha / \mathrm{RBV}$ therapy among CHC patients and determine rs12979860 polymorphism by HRM as a simple, fast, sensitive, inexpensive, sensitive and specific method.

Recently, several studies describing assays for IL28B detecting have been published (Falleti et al.,
2011; Moghaddam et al., 2011). These were sequencing, also several non-sequencing assays such as restriction fragment length polymorphism (RFLP), TaqMan PCR, amplification refractory mutation system polymerase chain reaction (ARMS-PCR) and allele-specific PCR. Most of them are expensive, time-consuming and they need specific probes and instruments.

We have developed a reliable, fast, simple, inexpensive, sensitive and specific HRM method for genotyping of IL28B rs12979860 SNPs that is more cost-effective than sequencing. The HRM genotyping results (to confirm the HRM method) showed $100 \%$ concordant with the PCRsequencing results.

Poon et al have recently reported, this method can be readily adopted by any molecular diagnostic laboratory with HRM capability and will be clinically beneficial in predicting treatment response in $\mathrm{HCV}$ genotype 1 infected patients, also this method was sensitive and cost-effective (Poon et al., 2012).

Out of 100 Iranian patients with chronic HCV, subtype 1a was the most common subtype (51\%) followed by subtype $3 \mathrm{a}(49 \%)$. The distribution of HCV genotype in the present study was very similar to other Iranian studies (Zali et al., 2000; Samimi-Rad et al., 2004; Keyvani et al., 2007) but is different from observations in other Middle Eastern countries. As an example the overcoming HCV genotype was $1 \mathrm{~b}$ in Turkey (Altuglu et al., 2008), 3a in Pakistan (Sajid et al., 2014) and 1b in Russia (Viazov et al., 1997). It is likely which differences in the race, routes of transmission, and different socioeconomic factors might describe this variation.

Liver enzymes (ALT, AST, and ALKP) are the key clinical appraisement for liver function, immune activation in HCV patients and SVR; but, the current study revealed no significant difference between liver enzymes levels, HCV genotype, IL28B rs12979860 polymorphism and SVR (Table 1, 3). Logistic regression analysis in the current study also demonstrated that pretreatment ALT, AST, and ALKP levels were not predictors of SVR in HCV patients. However, these results were consistent with the previous studies in that no associations were observed between these enzymes and IL28B rs12979860 polymorphism and SVR rates (Akkarathamrongsin et al., 2014; Eslam et al., 2014); in contrast, the results of the present study were consistent with a number of reports (Shi et al., 2012).

Liver enzymes levels were very important parameters for host factors that should be monitored carefully during 
pegIFN- $\alpha /$ RBV treatment. In conclusion, virological and biochemical markers (HCV viral load and serum ALT, AST, and ALKP levels) were applied in detecting and monitoring of HCV disease (Afshar and Mollaie., 2012).

Two of the powerful SVR predictors are virus-related: $\mathrm{HCV}$ viral load and HCV genotype. Effect of the baseline viral load with HCV genotype and IL28B rs 12979860 polymorphism on the treatment response was evaluated. It was demonstrated that baseline viral load was significantly higher in the patients infected with HCV-1a as compared to HCV-3a as well as in non-SVR patients compared with SVR patients $(\mathrm{p}=0.041)$ (Table 2). Previous reports have also confirmed these results (Martinez-Gomez et al., 2012; Domagalski et al., 2013).

In the patients of our study, the overall SVR rate was $56 \%(n=56)$. SVR rate was $18 \%$ in the HCV-1a patients and $38 \%$ in the $\mathrm{HCV}-3 \mathrm{a}$ patients. A recent work demonstrated that there were significantly relashionship between HCV genotype and SVR $(p=<0.001)$. A previous study on Iranian patients demonstrated that SVR rate in $\mathrm{HCV}-3$ was more than that in patients with $\mathrm{HCV}-1$ treated with pegIFN- $\alpha /$ RBV (Namazee et al., 2012).

Although an association between baseline viral load and IL28B rs12979860 polymorphism has been previously described (Ge et al., 2009; Rauch et al., 2010; Domagalski et al., 2013), in the present study, no relationship was observed between viral load and the IL28B polymorphisms ( $\mathrm{p}=0.127$ ).

Frequency of rs12979860 genotypes CC, CT, and TT in HCV genotype 1a was $10(10 \%), 35(35 \%)$, and $6(6 \%)$, respectively and in HCV genotype 3a, it was 13 (13\%), 31 (31\%), and $5(5 \%)$, respectively. The results of the present study indicate that the IL-28 rs12979860 CT genotype is the commonest genotype in $\mathrm{CHC}$ patients. These results were consistent (Zekri et al., 2014) and inconsistent with a number of studies (Sharafi et al., 2012).

Interestingly, various distributions of IL28B rs12979860 genotypes (protective rs12979860 CC genotype) among Caucasians, Asians, and Africans describe different rates of SVR in these populations. Previous studies have confirmed that rs 12979860 $\mathrm{CC}$ allele has different frequencies in the worldwide population: $\mathrm{CC}$ allele's frequency in African populations is $23 \%$ to $55 \%$, in European population is $52 \%$ to $80 \%$, in Southwest Asia is $75 \%$ to $98 \%$, and in East Asia is $90 \%$ to $100 \%$ (Thomas et al., 2009).

Alternatively, various SVR rates might be in part described by distribution of different rs12979860 alleles in different HCV genotypes. In the current study, a lower frequency of $\mathrm{CC}$ genotype was found in the $\mathrm{HCV}$-1a group in comparison with the HCV-3a (Table 3 ). In addition, it was demonstrated that the rs 1297860 CC genotype was associated with SVR in HCV genotypes 1/3. Relationship between IL28B rs12979860 alleles and pegIFN- $\alpha$ / RBV treatment has been represented in different studies (Ge et al., 2009; Suppiah et al., 2009; Balagopal et al., 2010). The present study showed that CC allele in HCV genotype 1 and CC/CT alleles in HCV genotype 3 had an important role in infection control and SVR rate in CC group was higher than that in TT group among Iranian patients with chronic hepatitis C 1/3 (CHC-1/3). Sharafi et al. represented that CC and CT alleles in rs 12979860 , responded to treatment better than homozygous TT allele (Sharafi et al., 2011). Effect of rs12979860 polymorphism on the response to pegIFN- $\alpha / \mathrm{RBV}$ treatment in patients infected with $\mathrm{HCV}-1$ has been extensively demonstrated. Subjects that carry CC allele have SVR rates of more than $80 \%$; so, this allele is considered to be favorable. By contrast, subjects with TT allele have SVR rates of less than 40\%; so, it is considered unfavorable. It is clear which genotyping of the rs 12979860 polymorphism is a strong predictor of the clinical outcome for $\mathrm{HCV}-1$ patients (Balagopal et al., 2010), but also for HCV-3 to a lesser extent (Mangia et al., 2010; Sarrazin et al., 2011).

SVR rates in CC, CT, and TT (IL28B rs12979860) were $18 \%, 34 \%$, and $4 \%$, respectively. In current study, an association was found between SVR rates and IL28B polymorphisms. Understanding the associations between various IL28B polymorphisms and SVR after treatment with pegIFN- $\alpha / \mathrm{RBV}$ is a major topic, because there is a debate over whether all untreated subjects should get triple therapy given the increased costs and possible adverse effects. In countries such as Iran, the analysis of offered strategies based on IL28B rs12979860 and SVR could be very useful in terms of cost-effectiveness. This analysis could also provide benefits related to adverse effects, treatment tolerance, and induction of viral drug resistance (Martinez-Gomez et al., 2012).

In conclusion, the HRM assay described herein was rapid, inexpensive, sensitive and accurate for detecting rs 12979860 alleles in CHC patients. This method can be readily adopted by any molecular diagnostic laboratory with HRM capability and will be clinically beneficial in predicting treatment response in HCV genotype 1 and 3 infected patients. As also, it was demonstrated that $\mathrm{CC}$ and $\mathrm{CT}$ alleles in $\mathrm{HCV}-3 \mathrm{a}$ and $\mathrm{CC}$ allele in $\mathrm{HCV}-1 \mathrm{a}$ were significantly associated with response to pegIFN- $\alpha / \mathrm{RBV}$ treatment. The present results may help identify subjects for whom the therapy might be successful.

\section{Acknowledgements}

We would like to thank all of the patients who participated in the study.

\section{References}

Afshar RM, Mollaie HR (2012). Detection of HBV resistance to lamivudine in patients with chronic hepatitis B using zip nucleic acid probes in Kerman, southeast of Iran. Asian Pac J Cancer Prev, 13, 3657-61.

Akkarathamrongsin S, Thong VD, Payungporn S, et al (2014). IFNL3 (IL28B) and IFNL4 polymorphisms are associated with treatment response in Thai patients infected with $\mathrm{HCV}$ genotype 1, but not with genotypes 3 and 6. J Med Virol, 86, $1482-90$.

Alavian SM, Tabatabaei SV, Keshvari M, et al (2010). Peginterferon alpha-2a and ribavirin treatment of patientswith haemophilia and hepatitis $\mathrm{C}$ virus infection: a singlecentre study of 367 cases. Liver Int, 30, 1173-80.

Altuglu I, Soyler I, Ozacar T, et al (2008). Distribution of hepatitis $\mathrm{C}$ virus genotypes in patients with chronic hepatitis C infection in Western Turkey. Int J Infect Dis, 12, 239-44. 
Antaki N, Craxi A, Kamal S, et al (2010). Theneglected hepatitis $\mathrm{C}$ virus genotypes 4, 5 and 6: an international consensus report. Liver Int, 30, 342-55.

Asselah T, Bieche I, Paradis V, et al (2007). Genetics, genomics, and proteomics: implications for the diagnosis and the treatment of chronic hepatitis C. Semin Liver Dis, 27, 13-27.

Balagopal A, Thomas DL, Thio CL (2010). IL28B and the control of hepatitis C virus infection. Gastroenterology, 139, $1865-76$.

Beinhardt S, Rutter K, Stattermayer AF, Ferenci P (2013). Revisiting the predictors of a sustained virologic response in the era of direct-acting antiviral therapy for hepatitis $\mathrm{C}$ virus. Clin Infect Dis, 56, 118-122.

Chen X, Sullivan PF (2003). Single nucleotide polymorphism genotyping: biochemistry, protocol, cost and throughput. Pharmacogenomics $J, 3,77-96$.

Dai CY, Huang JF, Hsieh MY, et al (2009). Insulin resistance predicts response to peginterferon-alpha/ribavirin combination therapy in chronic hepatitis $\mathrm{C}$ patients. $J$ Hepatol, 50, 712-8.

Domagalski K, Pawłowska M, Tretyn A, et al (2013). Impact of IL-28B polymorphisms on pegylated interferon plus ribavirin treatment response in children and adolescents infected with HCV genotypes 1 and 4. Eur J Clin Microbiol Infect Dis, 32, 745-54.

Eslam M, Leung R, Romero-Gomez M, et al (2014). IFNL3 polymorphisms predict response to therapy in chronic hepatitis C genotype 2/3 infection. J Hepatol, 61, 235-41.

European Association for the Study of the Liver. EASL Recommendations on Treatment of Hepatitis C 2014. From: http://www.easl.eu/_newsroom/latest-news/easlrecommendations-on-treatment-of-hepatitis-c-2014

Falleti E, Bitetto D, Fabris C, et al (2011). Role of interleukin 28B rs12979860 C/T polymorphism on the histological outcome of chronic hepatitis C: relationship with gender and viral genotype. J Clin Immunol, 31, 891-9.

Ge D, Fellay J, Thompson AJ, et al (2009). Genetic variation in IL28B predicts hepatitis $C$ treatment-induced viral clearance. Nature, 461, 399-401

Ghany MG, Nelson DR, Strader DB, et al (2011). American association for study of liver D. An update on treatment of genotype 1 chronic hepatitis $C$ virus infection: 2011 practice guideline by the American Association for the Study of Liver Diseases. Hepatology, 54, 1433-44.

Ghany MG, Strader DB, Thomas DL, Seeff LB (2009). Diagnosis, management, and treatment of hepatitis C: an update. Hepatology, 49, 1335-74.

Grebely J, Petoumenos K, Hellard M, et al (2010). Potential role for interleukin-28B genotype in treatment decisionmaking in recent hepatitis $\mathrm{C}$ virus infection. Hepatology, 52, 1216-24.

Kau A, Vermehren J, Sarrazin C (2008). Treatment predictors of a sustained virologic response in hepatitis B and C. $J$ Hepatol, 49, 634-51.

Keyvani H, Alizadeh AH,Alavian SM, et al (2007). Distribution frequency of hepatitis $\mathrm{C}$ virus genotypes in 2231 patients in Iran. Hepatol Res, 37, 101-3.

Keyvani H, Fazlalipour M, Monavari SH, et al (2012). Hepatitis $\mathrm{C}$ virus--proteins, diagnosis, treatment and new approaches for vaccine development. Asian Pac J Cancer Prev, 13, 5931-49.

Mangia A, Thompson AJ, Santoro R, et al (2010). An IL28B polymorphism determines treatment response of hepatitis $\mathrm{C}$ virus genotype 2 or 3 patients who do not achieve a rapid virologic response. Gastroenterology, 139, 821-7.

Martínez-Gomez LE, Chavez-Tapia NC, Burguete-García AI, et al (2012). IL28B polymorphisms predict the response to chronic hepatitis $\mathrm{C}$ virus infection treatment in a Mexican population. Ann Hepatol, 11, 876-81.

Melis R, Fauron C, McMillin G, et al (2011). Simultaneous genotyping of rs 12979860 and rs8099917 variants near the IL28B locus associated with HCV clearance and treatment response. J Mol Diagn, 13, 446-51.

Moghaddam A, Melum E, Reinton N, et al (2011). IL28B genetic variation and treatment response in patients with hepatitis $\mathrm{C}$ virus genotype 3 infection. Hepatology, 53, 746-54.

Namazee N, Sali S, Asadi S, et al (2012). Real response to therapy in chronic hepatitis $\mathrm{C}$ virus patients: a study from Iran. Hepat Mon, 12, 6151.

Poon KS, Ho SS, Tang JW, et al (2012). Targeting both rs12979860 and rs8099917 polymorphisms with a singletube high-resolution melting assay for IL28b genotyping. $J$ Clin Microbiol, 50, 3353-5.

Pourhoseingholi MA, Fazeli Z, Zali MR, et al (2010). Burden of hepatocellular carcinoma in Iran; Bayesian projection and trend analysis. Asian Pac J Cancer Prev, 11, 859-62.

Rauch A, Kutalik Z, Descombes P, et al (2010). Genetic variation in IL28B is associated with chronic hepatitis $\mathrm{C}$ and treatment failure: a genome-wide association study. Gastroenterology, 138, 1338-45.

Sajid A, Ayaz A, Raham Sh, et al. Genotyping of HCV RNA Reveals That 3a Is the Most Prevalent Genotype in Mardan, Pakistan. Advances in Virology, 2014, 1-5.

Samimi-Rad K, Nategh R, Malekzadeh R, et al (2004). Molecular epidemiology of hepatitis $\mathrm{C}$ virus in Iran as reflected by phylogenetic analysis of the NS5B region. J Med Virol, 74, 246-52.

Sarrazin C, Susser S, Doehring A, et al (2011). Importance of IL28B gene polymorphisms in hepatitis $C$ virus genotype 2 and 3 infected patients. J Hepatol, 54, 415-21.

Sharafi H, Pouryasin A, Alavian SM, et al (2012). Development and validation of a simple, rapid and inexpensive PCR-RFLP Method for genotyping of common IL28B polymorphisms: A useful pharmacogenetic tool for prediction of hepatitis $\mathrm{C}$ treatment response. Hepat Mon, 12, 190-5.

Shi X, Pan Y, Wang M, et al (2012). IL28B genetic variation is associated with spontaneous clearance of hepatitis $\mathrm{C}$ virus, treatment response, serum IL-28B levels in Chinese population. PLoS One, 7, 37054.

$\mathrm{Su}$ CH, Lin Y, Cai L (2013). Genetic factors, viral infection, other factors and liver cancer: an update on current progress. Asian Pac J Cancer Prev, 14, 4953-60.

Suppiah V, Moldovan M, Ahlenstiel G, et al (2009). IL28B is associated with response to chronic hepatitis $\mathrm{C}$ interferonalpha and ribavirin therapy. Nat Genet, 41, 1100-4.

Thomas DL, Thio CL, Martin MP, et al (2009). Genetic variation in IL28B and spontaneous clearance of hepatitis C virus. Nature, 461, 798-801.

Tsubota A, Kiyotaka F, Yoshihisa N, et al (2011). Peginterferon and ribavirin treatment for hepatitis $\mathrm{C}$ virus infection. World J Gastroenterol, 17, 419-432.

Viazov S, Kuzin S, Paladi N, et al (1997). Hepatitis C virus genotypes in different regions of the former Soviet Union (Russia, Belarus, Moldova, and Uzbekistan). J Med Virol, 53, 36-40.

Wohnsland A, Hofmann WP, Sarrazin C (2007). Viral determinants of resistance to treatment in patients with hepatitis C. Clin Microbiol Rev, 20, 23-38.

Yang JD, Roberts LR (2010). Hepatocellular carcinoma: a global view. Nat Rev Gastroenterol Hepatol, 7, 448-58.

Zali MR, Mayumi M, Raoufi M, et al (2000). Hepatitis C virus genotypes in the Islamic Republic of Iran: a preliminary study. East Mediterr Health J, 6, 372-7.

Zekri AR, Salama H, Medhat E, et al (2014). IL28B rs12979860 
Abolfazl Fateh et al

Gene polymorphism in Egyptian patients with chronic liver disease infected with HCV. Asian Pac J Cancer Prev, 15, 7213-8.

1880 Asian Pacific Journal of Cancer Prevention, Vol 16, 2015 